\title{
U.S. Department of the Interior Climate Science Centers
}

\section{What is a Climate Science Center?}

On September 14, 2009, the Secretary of the Interior signed a Secretarial Order (No. 3289) entitled, "Addressing the Impacts of Climate Change on America's Water, Land, and Other Natural and Cultural Resources." The Order effectively established the U.S. Department of the Interior (DOI) Climate Science Centers (CSCs), which will integrate DOI science and management expertise with similar contributions from our partners to provide information to support adaptation and mitigation efforts on both public and private lands, across the United States and internationally.

\section{Planning for Climate Change Research}

CSCs are research collaborations that will be guided by a U.S. Geological Survey (USGS) Center Director and hosted by a university or consortium of universities. Each CSC will bring together expertise from university and federal scientists to support climate change research and collaborations in a specific geographic area.

Priority science activities of the CSCs include the following:

- Use and creation of high resolution climate modeling information and derivative products in order to produce key information that is needed to forecast ecological and population responses at national, regional, and local levels;

- Integration of physical climate models with ecological-, habitat-, and population-response models;

- Development of models to forecast fish- and wildlife-population and habitat changes;

- Development of methods to assess vulnerability of species and habitats; and

- Development of standardized approaches to modeling, monitoring, data management, and decision support.

Boundaries of the CSCs are intended to be flexible depending on the science needs of a particular region. Because environmental science needs related to climate do not stop at political borders, science programs focused on these natural resources also should not be held to fixed borders. Likewise, the scientific capabilities of the CSCs will be directed toward meeting research needs, exclusive of geographic delineations.

\section{About the Southeast Climate Science Center}

The Southeast CSC, hosted by NC State University (NCSU), will collaborate with a number of other universities, State and Federal agencies, and nongovernmental organizations (NGOs) with interest and expertise in climate science. The primary partner for the Southeast CSC will be the Landscape Conservation Cooperatives (LCCs) in the Southeast, including the Appalachian, Gulf Coastal Plains and Ozarks, Gulf Coast Prairie, Peninsular Florida, and the South Atlantic. CSC collaborations are focused on common science priorities, addressing priority partner needs, minimizing redundancies in science, sharing scientific findings, and expanding understanding of climate change impacts in the Southeast.

One example of current research, funded in part by the Southeast CSC, includes the Southeast Regional Assessment Project (SERAP). Specific information about SERAP can be obtained at http://serap.er.usgs.gov/.

EXPLANATION

Miv Southeast Regional Assessment Project (SERAP)

- Approximate boundary Center (CSC)
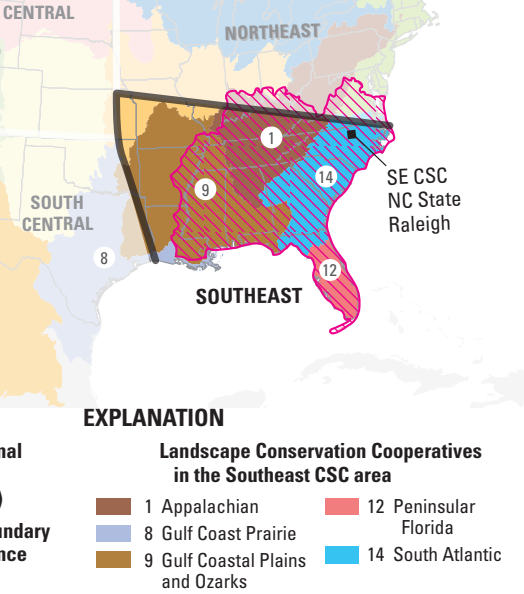
